Article

\title{
Bacillus amyloliquefaciens RWL-1 as a New Potential Strain for Augmenting Biochemical and Nutritional Composition of Fermented Soybean
}

\author{
Raheem Shahzad ${ }^{1,2}{ }^{(1)}$, Adeeb Shehzad ${ }^{3}$, Saqib Bilal ${ }^{4}$ and In-Jung Lee ${ }^{5, *}$ \\ 1 Basic and Applied Scientific Research Center, Imam Abdulrahman Bin Faisal University, P.O. Box 1982, \\ Dammam 31441, Saudi Arabia; rmshahzad@iau.edu.sa \\ 2 Department of Biology, College of Science, Imam Abdulrahman Bin Faisal University, P.O. Box 1982, \\ Dammam 31441, Saudi Arabia \\ 3 Department of Clinical Pharmacy, Institute for Research \& Medical Consultations (IRMC), Imam \\ Abdulrahman Bin Faisal University, P.O. Box 1982, Dammam 31441, Saudi Arabia; asmsiar@iau.edu.sa \\ 4 Natural and Medical Sciences Research Center, University of Nizwa, Nizwa 616, Oman; \\ saqib043@yahoo.com \\ 5 School of Applied Biosciences, Kyungpook National University, Daegu 41566, Korea \\ * Correspondence: ijlee@knu.ac.kr
}

Academic Editors: Francesco Cacciola, Alessia Fazio and Pierluigi Plastina Received: 13 April 2020; Accepted: 12 May 2020; Published: 18 May 2020

\begin{abstract}
Soybean (Glycine max L.) is a good source of natural antioxidants and commonly consumed as fermented products such as cheonggukjang, miso, tempeh, and sufu in Asian countries. The aim of the current study was to examine the influence of novel endophytic bacterial strain, Bacillus amyloliquefaciens RWL-1 as a starter for soybean fermentation. During fermentation, the cooked soybeans were inoculated with different concentrations ( $1 \%, 3 \%$, and $5 \%$ ) of B. amyloliquefaciens RWL-1. The changes in 2,2-diphenyl-1-picrylhydrazyl (DPPH), 2,2'-azino-bis (3-ethylbenzthiazoline-6-sulfonic acid) (ABTS) radical scavenging activities, total phenolic contents, isoflavones (Daidzin, Genistin, Glycitin, Daidzein, Glycitein, and Genistein), amino acids (aspartic acid, threonine, serine, glutamic acid, glycine, alanine, cysteine, valine, methionine, isoleucine, leucine, tyrosine, phenylalanine, lysine, histidine, arginine, and proline) composition, and minerals (calcium, copper, iron, potassium, magnesium, manganese, sodium, nickel, lead, arsenic, and zinc) were investigated. The level of antioxidants, total phenolic contents, isoflavones, and total amino acids were higher in fermented soybean inoculated with $1 \%$ B. amyloliquefaciens RWL-1 after $60 \mathrm{~h}$ of fermentation as compared to control, $3 \%$ and $5 \%$ B. amyloliquefaciens RWL-1. Additionally, fermented soybean inoculated with 5\% B. amyloliquefaciens RWL-1 showed the highest values for mineral contents. Changes in antioxidant activities and bioactive compounds depended on the concentration of the strain used for fermentation. From these results, we conclude that fermented soybean has strong antioxidant activity, probably due to its increased total phenolic contents and aglycone isoflavone that resulted from fermentation. Such natural antioxidants could be used in drug and food industries and can be considered to alleviate oxidative stress.
\end{abstract}

Keywords: fermented soybean; fermentation; antioxidant activity; amino acid; isoflavones; nutritional composition

\section{Introduction}

Soybean (Glycine max L.) is the most recognized source of plant protein, which plays a key role for human health. Soybean is a rich source of important nutritive constituents, such as carbohydrates, vitamins, minerals, saponins, isoflavones, flavonoids, and peptides that are of high therapeutic 
importance [1]. Twelve different kind isoflavones are found in soybeans and soy-containing products. These isoflavones refer to phytoestrogens which play an important role in the inhibition of osteoporosis and cardiovascular diseases due to their estrogenic activities [2]. Several studies have reported that a high soybean intake is associated with a low incidence of breast cancer in Asian countries [3]. At the same time, scientists are attracted to soybean because of its supply for different types of valuable minerals such as calcium, phosphorus, and iron [4]

Soybean is used as some unfermented products such as roasted and fried soybeans, and fermented as soy sauce, tempeh, Chinese douche, sufu, miso, natto, kanjang, doenjang, and cheonggukjang (CGJ) [5]. Fermentation has been used to preserve the spoilable foods since ancient times and the idea behind the process was especially where there was a lack of such foods. Recently, fermentation is applied to enhance active components responsible for improving health [6]. Complex organic compounds are broken down into smaller molecules during fermentation, which exerts physiological functions beyond their dietary properties. Fermentation can also result in a reduction of anti-nutritional components such as oxalic acids, proteinase-inhibitors, urease, and phytic acid [7]. Recent advancements in probiotic formulations revealed that many Bacillus strains have probiotic properties. Ushakova et al. [8] directed the importance of biofilms produced by Bacillus strains and their promising application in medical, veterinary, and pharmaceutical probiotic formulations. Equally, soybean has been implemented in bioprocessing concepts and yeast bioconversion to generate carotenoids and microbial oil that was further employed for novel oleogels formulation, thereby broadening the range of food applications $[9,10]$. The formulation technologies of selected potent strains would provide a better understanding of digestion and immune enhancement due to probiotic dietary supplements [11].

Fermented soybean with various microorganisms improves the nutritious properties due to the rise in free isoflavones, resulting in higher concentrations of aglycones, improved minerals, and amino acids [12-15]. Depending on their chemical forms metabolic fate of soybean isoflavones differ due to the structure itself. The chemical forms of the isoflavones are a limiting factor for absorption in the rumen and intestinal wall, and their metabolites such as aglycones influence the extent of absorption with more readily absorbed and more actively available than highly polar conjugated species [14]. The acetyl and malonyl glycosides are metabolized to glycosides during ingestion, which is hydrolyzed by microbes in the large intestine, to produce their respective aglycones daidzein, genistein, and glycitein [15]. However, an efficient method for safety and functionality enhancement of fermented soy foods is the use of Bacillus strains with desirable traits as a starter. Desirable characters of microbes to be used as starter for food fermentation consist of their potential to inhibit the growth of pathogenic microbes, the ability to produce bioactive metabolites and the capability to confer ideal organoleptic properties on fermented foods [16].

Therefore, the current study was carried out with our previously isolated B. amyloliquefaciens RWL-1 which was initially isolated from rice seeds and has been reported for antifungal potential and various secondary metabolites (phytohormones and organic acids) and novel compound ((S)-2-hydroxyN-((S)-1-((S)-8-hydroxy-1-oxoisochroman-3-yl)-3-methylbutyl)-2-((S)-5-oxo-2,5-dihydrofuran-2-yl) acetamide) production [17-20]. The objectives of the current study were to systematically evaluate the total phenolic contents and phytochemical substances to get the overall in vitro antioxidant capacities of fermented soybean using B. amyloliquefaciens RWL-1. Especially, this study focused on isoflavone contents, total amino acids, and minerals to find the relationships between the production and distribution of bioactive compounds in fermented soybean. In addition, we identified and quantified the correlation of antioxidants and their activities in fermented soybean. Developments from this study should expect to help consumers with suggestions to choose commercially fermented soybean and provide appropriate evidence to use fermented soybean in pharmaceutical, food, and cosmetic industries. 


\section{Results}

\subsection{Total Phenolic Contents}

In the current study, a significant variation $(P<0.05)$ in total phenolic contents was observed among the unfermented and fermented soybean with various percentages of B. amyloliquefaciens RWL-1 as summarized in Figure 1. The results revealed that the soybean fermentation with $1 \%$ B. amyloliquefaciens RWL-1 exhibit a significantly higher amount of total phenolic contents (TPC) with $181.50 \%$ increase in soybean fermented with $1 \%$ B. amyloliquefaciens RWL-1 followed by $151.93 \%$ and $60.31 \%$ increase in soybean fermented with $3 \%$ and $5 \%$ B. amyloliquefaciens respectively, as compared to control (Figure 1).

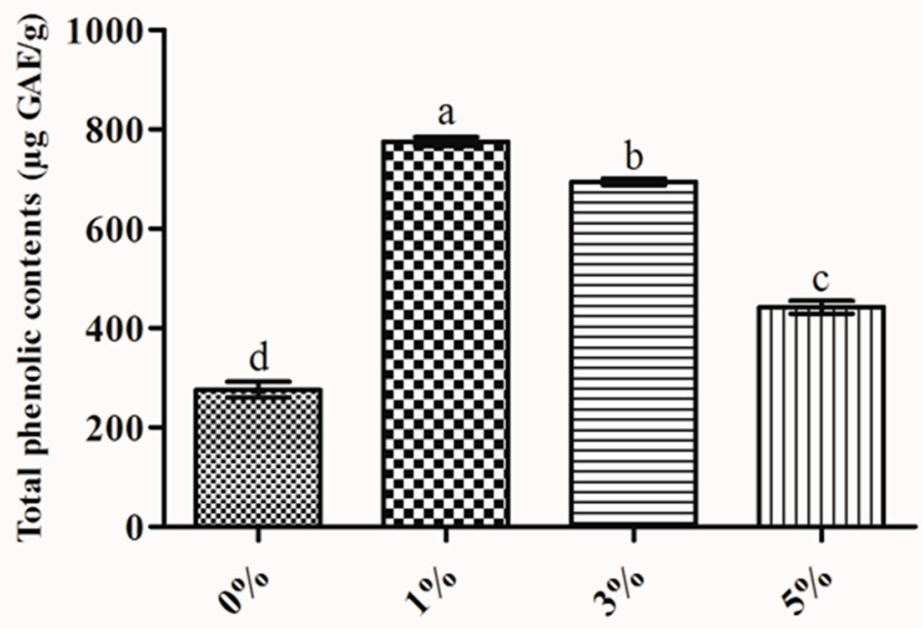

Figure 1. Total phenolic contents of non-fermented and fermented soybean using different concentrations $(1 \%, 3 \%$, and $5 \%$ ) of the B. amyloliquefaciens RWL-1. Values are means of three independents experiments. The letters $a, b, c$, and $d$ indicate significant differences $(P \leq 0.05)$ by Duncan's multiple range tests (DMRT).

\subsection{Antioxidants}

In the current study, the B. amyloliquefaciens RWL-1 fermentation significantly maximizes the free radical scavenging potential as shown in Figure 2. The results showed that the higher free 2,2-diphenyl-1-picrylhydrazyl (DPPH) scavenging activity was recorded in soybean fermented with $323.39 \%$ increase in soybean fermented with $1 \%$ B. amyloliquefaciens RWL-1 followed by $171.02 \%$ and $59.65 \%$ increase in soybean fermented with $3 \%$ and $5 \%$ respectively, as compared to control (Figure 2).

In our study, the B. amyloliquefaciens RWL-1 fermentation interestingly enhanced the 2,2'-azino-bis (3-ethylbenzthiazoline-6-sulfonic acid) (ABTS) scavenging potential of soybean as compared to unfermented soybean (Figure 2). The results revealed the maximum scavenging was found in soybean fermented with $121.18 \%$ increase in soybean fermented with $1 \%$ B. amyloliquefaciens RWL-1 followed by $71.30 \%$ and $35.67 \%$ increase in soybean fermented with $3 \%$ and $5 \%$ respectively, as compared to unfermented soybean (Figure 2). 

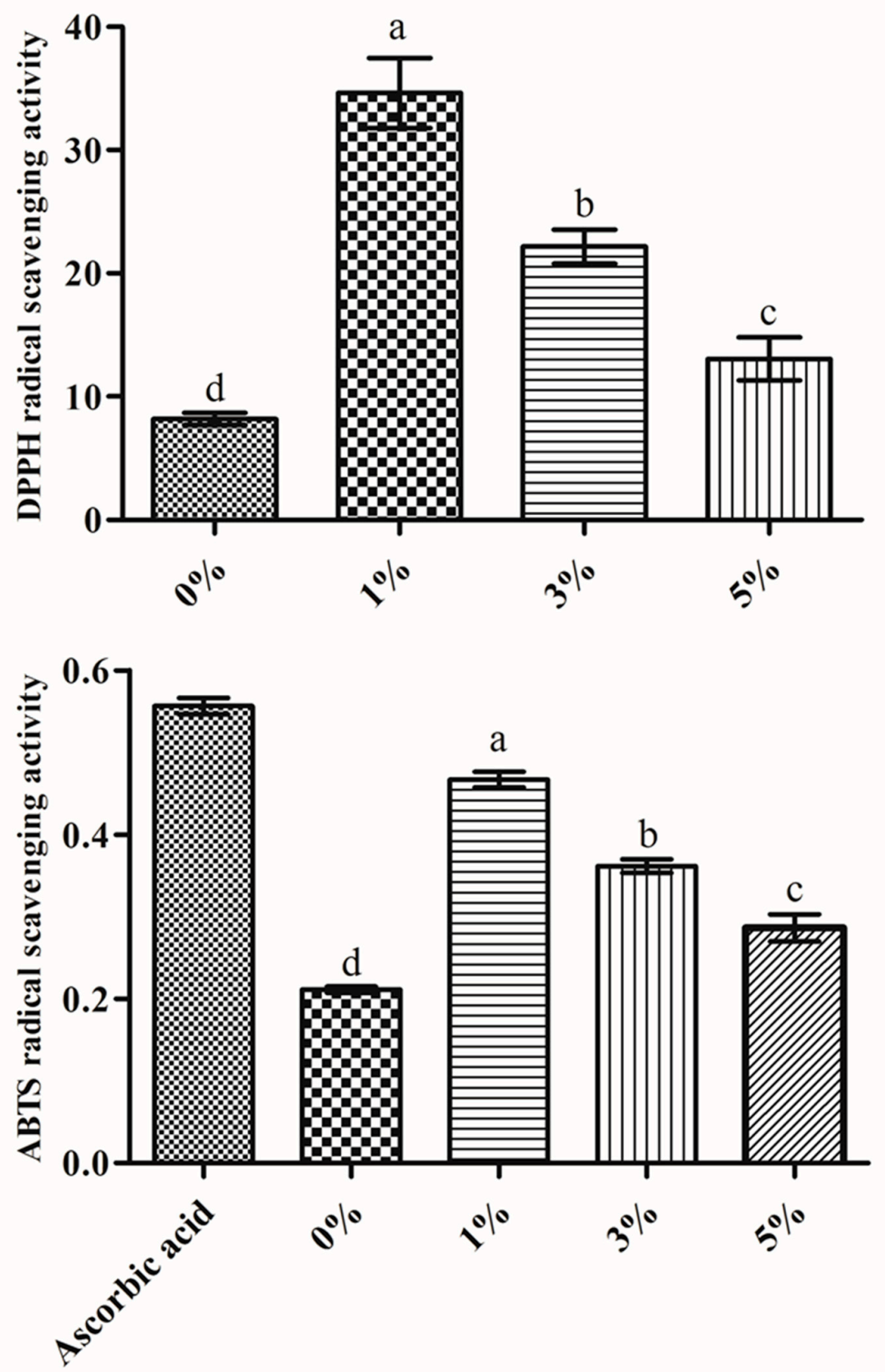

Figure 2. 2,2-diphenyl-1-picrylhydrazyl (DPPH) radical-scavenging and 2,2'-azino-bis (3ethylbenzthiazoline-6-sulfonic acid) (ABTS) radical scavenging activity of non-fermented and fermented soybean using different concentrations $(1 \%, 3 \%$, and $5 \%$ ) of the B. amyloliquefaciens RWL- 1 . The letters $\mathrm{a}, \mathrm{b}, \mathrm{c}$, and $\mathrm{d}$ indicate significant differences $(P \leq 0.05)$ by DMRT.

\subsection{Total Amino Acids Composition}

In our study, B. amyloliquefaciens RWL-1 fermentation significantly improved amino acids composition of fermented soybean as compared to non-fermented soybean. The increased amount of total amino acids were recorded in soybean fermented with $1 \%$ B. amyloliquefaciens RWL-1 with $329.26 \%$ increase, followed by $3 \%$ and $5 \%$ B. amyloliquefaciens RWL-1 with $185.35 \%$ and $57.86 \%$ increase respectively, while the less amount was recorded in unfermented soybean (Table 1). More specifically, aspartic acid, threonine, glutamic acid, glycine, alanine, cysteine, valine, methionine, isoleucine, leucine, tyrosine, phenylalanine, lysine, histidine, arginine, and proline was increased in soybean fermented with $1 \%$ B. amyloliquefaciens RWL-1 with $222.22 \%, 160.56 \%, 290.43 \%, 250.89 \%, 199.73 \%, 58.52 \%, 183.29 \%$, 
$511.11 \%$, 221.20\%, 314.23\%, 123.17\%, 226.58\%, 216.21\%, 402.30\%, 105.39\%, and 255.13\% followed by soybean fermented with 3\% B. amyloliquefaciens RWL-1 with 211.11\%, 53.89\%, 141.74\%, 114.29\%, 145.7\%, $215.66 \%, 155.06 \%, 324.07 \%, 142.41 \%, 178.47 \%, 112.60 \%, 126.88 \%, 81.08 \%, 399.23 \%, 62.63 \%$, and $166.57 \%$ and soybean fermented with 5\% B. amyloliquefaciens RWL-1 with 68.89\%, 13.89\%, 54.35\%, 66.07\%, $36.29 \%$, 9.89\%, 30.35\%, 85.19\%, 55.59\%, 59.85\%, 29.67\%, 25.43\%, 34.75\%, $13.08 \%, 44.06 \%$, and $45.75 \%$, respectively, as compared with non-fermented soybean (Table 1). Only serine was reduced with 13.79\%, $1.72 \%$, and $1.72 \%$ decreased in soybean fermented with $1 \%, 2 \%$, and $5 \%$ B. amyloliquefaciens RWL-1 respectively as compared with non-fermented soybean. (Table 1)

Table 1. Amino acids contents in non-fermented and fermented soybean with various concentrations $(1 \%, 3 \%$, and $5 \%)$ of B. amyloliquefaciens RWL-1.

\begin{tabular}{|c|c|c|c|c|}
\hline Amino Acid mg/0.1 g & Control & 1\% RWL-1 & 3\% RWL-1 & 5\% RWL-1 \\
\hline aspartic acid & $0.45 \pm 0.04^{c}$ & $1.54 \pm 0.10^{a}$ & $1.40 \pm 0.14^{\mathrm{a}}$ & $0.76 \pm 0.03^{b}$ \\
\hline Threonine & $1.8 \pm 0.01^{\mathrm{d}}$ & $4.69 \pm 0.13^{a}$ & $2.77 \pm 0.09^{b}$ & $2.05 \pm 0.31^{c}$ \\
\hline Serine & $0.58 \pm 0.03^{a}$ & $0.50 \pm 0.06^{b}$ & $0.57 \pm 0.01^{a}$ & $0.57 \pm 0.01^{a}$ \\
\hline glutamic acid & $2.3 \pm 0.01^{d}$ & $8.98 \pm 0.62^{a}$ & $5.56 \pm 0.30^{b}$ & $3.55 \pm 0.04^{c}$ \\
\hline Glycine & $1.12 \pm 0.02^{\mathrm{d}}$ & $3.93 \pm 0.15^{a}$ & $2.4 \pm 0.23^{b}$ & $1.86 \pm 0.43^{c}$ \\
\hline Alanine & $7.44 \pm 0.33^{d}$ & $22.30 \pm 0.70^{a}$ & $18.28 \pm 0.46^{b}$ & $10.14 \pm 0.50^{c}$ \\
\hline Cysteine & $3.64 \pm 0.37^{c}$ & $5.77 \pm 0.28^{b}$ & $11.49 \pm 0.32^{a}$ & $4.00 \pm 0.13^{c}$ \\
\hline Valine & $4.25 \pm 0.21^{\mathrm{d}}$ & $12.04 \pm 0.19^{a}$ & $10.84 \pm 0.15^{b}$ & $5.54 \pm 0.36^{c}$ \\
\hline Methionine & $1.08 \pm 0.09^{d}$ & $6.60 \pm 0.24^{a}$ & $4.58 \pm 0.39^{b}$ & $2.00 \pm 0.18^{c}$ \\
\hline Isoleucine & $3.49 \pm 0.23^{d}$ & $11.21 \pm 0.49^{a}$ & $8.46 \pm 0.23^{b}$ & $5.43 \pm 0.32^{c}$ \\
\hline Leucine & $5.48 \pm 0.37^{\mathrm{d}}$ & $22.70 \pm 0.38^{a}$ & $15.26 \pm 0.37^{b}$ & $8.76 \pm 0.44^{c}$ \\
\hline Tyrosine & $2.46 \pm 0.25^{c}$ & $5.49 \pm 0.31^{a}$ & $5.23 \pm 0.29^{a}$ & $3.19 \pm 0.35^{b}$ \\
\hline Phenylalanine & $3.46 \pm 0.25^{\mathrm{d}}$ & $11.30 \pm 0.59^{a}$ & $7.85 \pm 0.11^{b}$ & $4.34 \pm 0.38^{c}$ \\
\hline Lysine & $2.59 \pm 0.31^{\mathrm{d}}$ & $8.19 \pm 0.26^{a}$ & $4.69 \pm 0.23^{b}$ & $3.49 \pm 0.30^{c}$ \\
\hline Histidine & $1.30 \pm 0.08^{b}$ & $6.53 \pm 0.39^{a}$ & $6.49 \pm 0.46^{a}$ & $1.47 \pm 0.07^{b}$ \\
\hline Arginine & $4.63 \pm 0.26^{\mathrm{d}}$ & $9.51 \pm 0.34^{\mathrm{a}}$ & $7.53 \pm 0.37^{b}$ & $6.67 \pm 0.37^{c}$ \\
\hline Proline & $3.41 \pm 0.25^{\mathrm{d}}$ & $12.11 \pm 0.52^{a}$ & $9.09 \pm 0.64^{b}$ & $4.97 \pm 0.38^{c}$ \\
\hline Total Amino Acids & $47.70 \pm 3.25^{\mathrm{d}}$ & $204.77 \pm 6.38^{a}$ & $136.11 \pm 4.97^{b}$ & $75.30 \pm 3.49^{c}$ \\
\hline
\end{tabular}

Values in rows followed by different letters $(\mathrm{a}, \mathrm{b}, \mathrm{c}$, and $\mathrm{d}$ ) are significantly different at $P<0.05$ revealed by DMRT tests.

\subsection{Determination of Isoflavones}

In the current study, isoflavones contents were estimated in fermented soybean in comparison with non-fermented soybean. In our study, the soybean fermented with B. amyloliquefaciens RWL-1 displayed enhanced isoflavones contents as compared to non-fermented soybean (Table 2). The results of the current study revealed that fermentation of soybean with various percentages of B. amyloliquefaciens RWL-1 significantly increased the total isoflavones. Total isoflavones were significantly improved with $32.71 \%$ increase in soybean fermented with $1 \%$ B. amyloliquefaciens RWL-1 followed by $18.47 \%$ increase in soybean fermented with 3\% B. amyloliquefaciens RWL-1, while the soybean fermented with $5 \%$ B. amyloliquefaciens RWL-1 displayed 4.49\% decrease in total isoflavones contents as compared to non-fermented soybean (Table 2). More specifically, significantly increased amount of daidzin, genistin, and glycitin with $96.13 \%, 53.21 \%$, and $225.40 \%$ increase were recorded in soybean fermented with $1 \%$ B. amyloliquefaciens RWL-1 with, followed by $84.96 \%, 36.94 \%$, and $189.68 \%$ increase respectively, in soybean fermented with 3\% B. amyloliquefaciens RWL-1 and with $64.60 \%, 11.54 \%$, and $91.95 \%$ increase 
in soybean fermented with 5\% B. amyloliquefaciens RWL-1, respectively, as compared to non-fermented soybean (Table 2). While, daidzein, glycitein and genistein were significantly reduced with $61.18 \%$, $72.98 \%$, and $64.15 \%$ decrease, respectively, upon fermentation with 5\% B. amyloliquefaciens RWL-1 followed by $51.53 \%, 48.34 \%$, and $59.13 \%$ decrease in soybean fermented with $3 \%$ B. amyloliquefaciens RWL-1 43.13\%, 39.78\%, and 36.95\% decrease in soybean fermented with 1\% B. amyloliquefaciens RWL-1, respectively, as compared to non-fermented soybean (Table 2).

Table 2. Isoflavones quantification in non-fermented and fermented soybean with various concentrations (1\%, 3\%, and 5\%) of B. amyloliquefaciens RWL-1.

\begin{tabular}{ccccc}
\hline Isoflavone mg/kg & Control & $\mathbf{1 \%}$ RWL-1 & $\mathbf{3 \% ~ R W L - 1}$ & $\mathbf{5 \% ~ R W L - 1}$ \\
\hline Daidzin & $154.32 \pm 1.76^{\mathrm{d}}$ & $302.67 \pm 3.12^{\mathrm{a}}$ & $285.44 \pm 2.54^{\mathrm{b}}$ & $254.02 \pm 2.74^{\mathrm{c}}$ \\
\hline Genistin & $260.56 \pm 3.14^{\mathrm{d}}$ & $399.21 \pm 2.43^{\mathrm{a}}$ & $356.82 \pm 3.92^{\mathrm{b}}$ & $290.64 \pm 4.51^{\mathrm{c}}$ \\
\hline Glycitin & $25.98 \pm 2.45^{\mathrm{d}}$ & $84.54 \pm 1.32^{\mathrm{a}}$ & $75.26 \pm 1.33^{\mathrm{b}}$ & $49.87 \pm 0.48^{\mathrm{c}}$ \\
\hline Daidzein & $183.72 \pm 3.37^{\mathrm{a}}$ & $104.48 \pm 4.83^{\mathrm{b}}$ & $89.04 \pm 1.65^{\mathrm{c}}$ & $71.32 \pm 1.12^{\mathrm{d}}$ \\
\hline Glycitein & $126.86 \pm 2.28^{\mathrm{a}}$ & $76.39 \pm 2.35^{\mathrm{b}}$ & $63.53 \pm 2.74^{\mathrm{c}}$ & $34.27 \pm 0.98^{\mathrm{d}}$ \\
\hline Genistein & $42.65 \pm 2.05^{\mathrm{a}}$ & $26.89 \pm 0.66^{\mathrm{b}}$ & $17.43 \pm 1.78^{\mathrm{c}}$ & $15.29 \pm 1.05^{\mathrm{d}}$ \\
\hline Total isoflavones & $749.09 \pm 4.72^{\mathrm{c}}$ & $994.18 \pm 6.91^{\mathrm{a}}$ & $887.52 \pm 6.35^{\mathrm{b}}$ & $715.41 \pm 4.69^{\mathrm{d}}$ \\
\hline
\end{tabular}

Values in rows followed by different letters $(\mathrm{a}, \mathrm{b}, \mathrm{c}$, and $\mathrm{d})$ are significantly different at $P<0.05$ revealed by DMRT tests.

\subsection{Assessment of Minerals}

In the current study, 11 minerals viz. calcium $(\mathrm{Ca})$, copper $(\mathrm{Cu})$, iron $(\mathrm{Fe})$, potassium $(\mathrm{K})$, magnesium (mg), manganese $(\mathrm{Mn})$, sodium $(\mathrm{Na})$, nickel $(\mathrm{Ni})$, lead $(\mathrm{Pb})$, arsenic (As), and zinc $(\mathrm{Zn})$ were estimated in fermented and non-fermented soybean. The fermentation with various percentages of B. amyloliquefaciens RWL-1 revealed improved mineral contents of soybean as compared to non-fermented soybean (Table 3). The highest total mineral contents were observed in soybean fermented with 5\% B. amyloliquefaciens RWL-1 with $28.68 \%$ increase followed by $12.23 \%$ and $5.76 \%$ increase in soybean fermented with $3 \%$ and $1 \%$, respectively as compared to non-fermented soybean. More specifically the soybean fermented with 5\% B. amyloliquefaciens RWL-1 enhanced the level of Ca, $\mathrm{Fe}, \mathrm{K}, \mathrm{Mg}$, Mn, Na, and Zn by 10.14\%, 181.07\%, 28.83\%, 38.70\%, 100.38\%, 315.86\%, and 24.62\% increase followed by soybean fermented with 3\% B. amyloliquefaciens RWL-1 resulting enhanced Ca (7.90\%), Fe (89.37\%), K (13.74\%), Mg (15.82\%), Mn (98.16\%), Na (59.34\%), and Zn (15.89\%), subsequently, soybean fermented with $1 \%$ B. amyloliquefaciens RWL-1 resulting enhanced Ca (4.57\%), Fe (40.01\%), $\mathrm{K}(3.78 \%), \mathrm{Mg}(12.03 \%), \mathrm{Mn}(95.87 \%)$, Na (127.311\%), and Zn (15.89\%) as compared to non-fermented soybean (Table 3). However, the $\mathrm{Ni}$ and $\mathrm{Cu}$ were significantly decreased in soybean upon fermentation. The reduced amount of $\mathrm{Cu}$ with $34.99 \%$ decrease was recorded in soybean fermented with $1 \%$ B. amyloliquefaciens RWL-1 followed by $14.58 \%$ and $13.53 \%$ decrease in soybean fermented with $3 \%$ and 5\% B. amyloliquefaciens RWL-1 respectively as compared to non-fermented soybean (Table 3). Likewise, reduced amount of $\mathrm{Ni}$ with $68.766 \%$ decrease was recorded in soybean fermented with $1 \%$ B. amyloliquefaciens RWL-1 followed by $35.98 \%$ and $15.68 \%$ decrease in soybean fermented with $3 \%$ and $5 \%$ B. amyloliquefaciens RWL-1 respectively as compared to non-fermented soybean (Table 3). Moreover, $\mathrm{As}$ and $\mathrm{Pb}$ were not detected in fermented and non-fermented soybean. 
Table 3. Minerals analysis in non-fermented and fermented soybean with various concentrations ( $1 \%$, $3 \%$, and $5 \%$ ) of B. amyloliquefaciens RWL-1.

\begin{tabular}{ccccc}
\hline Minerals (mg/kg) & Control & $\mathbf{1 \%}$ RWL-1 & 3\% RWL-1 & $\mathbf{5 \% ~ R W L - 1 ~}^{\text {( }}$ \\
\hline Calcium & $1754.41 \pm 12^{\mathrm{d}}$ & $1834.64 \pm 19^{\mathrm{c}}$ & $1893.32 \pm 37^{\mathrm{b}}$ & $1932.35 \pm 25^{\mathrm{a}}$ \\
\hline Copper & $23.72 \pm 0.15^{\mathrm{a}}$ & $15.42 \pm 0.93^{\mathrm{c}}$ & $20.26 \pm 0.14^{\mathrm{b}}$ & $20.51 \pm 1.13^{\mathrm{b}}$ \\
\hline Iron & $44.23 \pm 1.54^{\mathrm{d}}$ & $61.93 \pm 0.73^{\mathrm{c}}$ & $83.76 \pm 1.91^{\mathrm{b}}$ & $124.32 \pm 1.24^{\mathrm{a}}$ \\
\hline Potassium & $9945 \pm 34.03^{\mathrm{d}}$ & $10321 \pm 23.32^{\mathrm{c}}$ & $11322 \pm 24.32^{\mathrm{b}}$ & $12813 \pm 43.28^{\mathrm{a}}$ \\
\hline Magnesium & $787.54 \pm 23.03^{\mathrm{d}}$ & $882.32 \pm 11.36^{\mathrm{c}}$ & $912.16 \pm 31.2^{\mathrm{b}}$ & $1092.33 \pm 32.5^{\mathrm{a}}$ \\
\hline Manganese & $47.29 \pm 0.14^{\mathrm{c}}$ & $92.63 \pm 2.76^{\mathrm{b}}$ & $93.71 \pm 4.76^{\mathrm{a}}{ }^{\mathrm{b}}$ & $94.76 \pm 3.43^{\mathrm{a}}$ \\
\hline Sodium & $58.51 \pm 3.62^{\mathrm{d}}$ & $133.87 \pm 3.54^{\mathrm{b}}$ & $93.23 \pm 2.32^{\mathrm{c}}$ & $243.32 \pm 3.54^{\mathrm{a}}$ \\
\hline Nickel & $7.78 \pm 1.24^{\mathrm{a}}$ & $2.43 \pm 0.07^{\mathrm{d}}$ & $4.98 \pm 1.12^{\mathrm{c}}$ & $6.56 \pm 1.32^{\mathrm{b}}$ \\
\hline Zinc & $29.32 \pm 1.76^{\mathrm{c}}$ & $33.98 \pm 1.79^{\mathrm{b}}$ & $33.98 \pm 1.79^{\mathrm{b}}$ & $36.54 \pm 1.03^{\mathrm{a}}$ \\
\hline Total Minerals & $12715.50 \pm 41^{\mathrm{d}}$ & $13449.18 \pm 27^{\mathrm{c}}$ & $14271.04 \pm 36^{\mathrm{b}}$ & $16363.42 \pm 17^{\mathrm{a}}$ \\
\hline
\end{tabular}

Values in rows followed by different letters are significantly different at $P<0.05$ revealed by DMRT tests.

\section{Discussion}

Fermented food has been a rich source of nutrients for a long time. Fermented foods are considered a rich source of various health beneficial constituents such as minerals, vitamins, antioxidants, folic acids, and fibers [21]. The consumption of fermented foods boosts our immune system, fights against inflammation, assists digestion, strengthens bones, enhances energy, balance cholesterol level, maintains the proper blood pressure and contributes in maintaining the youthful skin [22]. The fermented foods are generally available in the food market as dairy products that contain live microbe and also available in drug store as tablets and supplements which contain lyophilized microbes or its constituents which promote health benefits [23].

Soybean is considered a rich source of proteins, fatty acids, minerals, vitamins, isoflavones, amino acids, and carbohydrates [24]. Soybeans are consumed either directly as unfermented or indirectly as fermented soybean [25]. Various types of fermented soybeans are consumed and are very famous in Asian countries. Among other fermented soybeans, CGJ are popular fermented soybean consumed in South Korea and is considered a rich source of health beneficial constituents [12,13]. Keeping in view the nutritional and health beneficial potential of fermented soybean (Cheonggukjang (CGJ)), the current study was undertaken using B. amyloliquefaciens RWL-1. Seed-borne endophytic B. amyloliquefaciens RWL-1 was isolated from rice seed and has been reported for antifungal activity and various secondary metabolites and novel compound production [17-20]. The soybean fermented with various concentrations of B. amyloliquefaciens RWL-1 enhanced the total phenolic contents as compared with non-fermented soybean (Figure 1). Total phenolic content is a group of important bioactive metabolites, often investigated in scientific studies. Phenolic contents are considered important in functional food and pharmaceutics industries because of their free radical scavenging potential [26]. Similar results of enhanced total phenolic contents in soybean fermented with various probiotic B. subtilis has been previously reported $[12,13]$. Moreover, similar results of enhanced TPC of fermented soybean were $644 \pm 11.20 \mathrm{lg} / \mathrm{g}$ after $48 \mathrm{~h}$ fermentation is reported [27]. Likewise, another study reported $21 \%$ and $35 \%$ increase in TPC in soybean fermented with naturally occurring bacteria (soybean was left to ferment by naturally occurring microbes) and B. subtilis TN51, respectively [28]. However, the results of the current study reported comparatively increased $(181.50 \%)$ amount of TPC in soybean fermented with $1 \%$ of $B$. amyloliquefaciens. The differences might be due to difference in soybean cultivars and microbes concentrations used as a starter $[12,13,29]$.

2,2-diphenyl-1-picrylhydrazyl (DPPH) and 2,2-azinobis (3-ethylbenzothiazoline-6-sulfonic acid) (ABTS) are the commonly used to assess antioxidant activities [30]. DPPH is a cationic free radical and is based on an electron based reaction which is considered as an important arbitrator for investigating the antioxidant potentials of any compound. The DPPH scavenging potential is indicated by the degree of 
reduction and resulted in discoloration of tested samples [31]. The ABTS is generated by reacting with a strong oxidizing agent (e.g., potassium permanganate or potassium persulfate) with the ABTS salt [30]. The reduction of the blue-green ABTS radical by hydrogen-donating antioxidants is measured by the suppression of its characteristic long-wave absorption spectrum. However, the ABTS assay measures the relative ability of antioxidants to scavenge the ABTS generated in aqueous phase [30]. In the current study, the fermentation with B. amyloliquefaciens RWL-1 improves the antioxidants potential of soybean used in CGJ (Figure 2). Similar results of improved antioxidants potential of fermented soybean have been reported by Ali et al. [13]. They reported the improvement in DDPH radical scavenging activity by $94.24 \% \pm 0.83 \%$ increase of soybean fermented with $1 \%$ B. subtilis. Similarly, Cho et al. [32] reported the increased DPPH radical scavenging activity by $53.6 \%-93.9 \%$ after $60 \mathrm{~h}$ in soybean fermented with B. subtilis CS90. Likewise, Shon et al. [33] also reported DPPH radical scavenging activity by $69 \%-87 \%$ of soybean fermented with B. megaterium. However, comparatively, soybean fermentation with $1 \%$ B. amyloliquefaciens RWL-1 in current study revealed higher DPPH radical scavenging activity with $323.39 \%$ increase. The antioxidants data of the current study suggest that soybean fermented with $1 \%$ B. amyloliquefaciens exhibit enhanced and improved antioxidants. Similarly, ABTS assessment of soybean fermented with B. amyloliquefaciens exhibited increased ABTS scavenging activity as shown in Figure 2. A similar result of enhanced ABTS scavenging activity of soybean fermented with conventional probiotic B. subtilis by $86 \%$ is reported [13]. Likewise, Shin et al. [34] also reported the enhanced ABTS scavenging potential of soybean fermented with B. subtilis. Another study reported $91.06 \%$ and $81.12 \%$ ABTS scavenging activities in soybean fermented with Seoritae and Seormoktae sp. [35]. The current study revealed the maximum scavenging with $121.18 \%$ increase in soybean fermented with $1 \%$ B. amyloliquefaciens RWL-1. Recently, many researchers have linked the increased antioxidants potential of fermented soybean with flavonoids contents of fermented soybean [36]. The flavonoids contents of fermented soybean which could respond to generates ions which further extinguish free radicals and resulting in the axing of free radicals chain reaction [37].

The term amino acid refers to the structural unit of proteins and natural peptides. They are also precursors of very important non-proteinogenic biological compounds [38]. The increase in amino acids contents of soybean fermented with B. amyloliquefaciens RWL-1 is in line with the results is reported [13]. They reported the enhanced amino acids levels in soybean fermented with probiotic B. subtilis (KCTC 13241). They reported the highest amount of total amino acids $(7.430 \pm 0.62 \mathrm{mg} / \mathrm{g})$ in soybean fermented $1 \%$ B. subtilis among the various concentration of conventional probiotic B. subtilis, however in the current we found the highest amount $(204.77 \pm 6.38 \mathrm{mg} / 0.1 \mathrm{~g})$ of total amino acids with comparatively higher percentage of increase in soybean fermented with $1 \%$ B. amyloliquefaciens RWL-1. (Table 1). Similarly another study reported by Sarkar et al. [39], revealed a 60-fold increase in amino acid of fermented soybean with B. subtilis. Likewise, Dajanta et al. [40] investigated the essential amino acids and free amino acids in traditionally fermented soybean (thua nao) and revealed the essential amino acid profile of thua nao within the range of $20.23 \%$ to $35.41 \%$ with most abundantly Trp, Leu, and Lys contents. Similarly in some other studies focused on the amino acids profile of chungkukjang prepared with Bacillus sp. revealed the presence of amino acids at considerable amount of 53\% [41]. The increase in amino acid contents in soybean fermented with B. amyloliquefaciens RWL-1 is linked with amino acids production potential of B. amyloliquefaciens RWL-1 [42]. The amino acids presented as essential nutrients for health-promoting activities [43]. Therefore, their supplementation or enhancement in food is greatly required. The amino acids data of the current study suggest that soybean fermented with $1 \%$ B. amyloliquefaciens are a rich source of protein and exhibit favorable amino acids profile.

Isoflavones contents of soybean have been widely known for their beneficial health properties and have been recognized as important dietary supplements [44]. Soybean contains $\beta$-D-glucosides (daidzin, glycitin, and genistin) and aglycones (daidzein, glycitein, and genistein) isoflavones. In the current study, $\beta$-D-glucosides (daidzin, glycitin, and genistin) were significantly increased upon fermentation with B. amyloliquefaciens RWL-1 while the aglycones (daidzein, glycitein, and genistein) 
were significantly decreased upon fermentation with B. amyloliquefaciens RWL-1 (Table 2). Generally, soybeans are composed of glycone and aglycone as two classes of isoflavones. However, the compositions of various types of glycine and aglycone isoflavones vary in soybean food because of their varieties and processing techniques [45]. Generally, isoflavones are present in glycone form and transformed into aglycone during microbial fermentation [46]. The transformation of various isoflavones to other compounds as a result of high temperature and high steam pressure during fermentation is reported [47]. The loss and reduction in isoflavones are possibly due to thermal degradation and leaching in water [33]. The increased total isoflavones contents of fermented soybean are widely reported $[12,48]$. However, the changes in the Isoflavones contents of fermented soybean might be due to the differences in processing techniques and temperature [34]. The similar results of enhanced daidzin, glycitin, and genistin while reduced daidzein, glycitein, and genistein upon fermentation is reported by Ali et al. [13] Likewise, Cho et al. [32] reported 64\% the decrease in isoflavones in fermented soybean. Hwang et al. [35] reported the increase in aglycone isoflavones while the decrease in glycone isoflavones in fermented soybean. While another study reported that aglycone form of isoflavones could not be expected during tempeh (Indonesian fermented soybean) fermentation [49]. Conversely, another study reported increased aglycone isoflavones only at the beginning of fermentation but did not increase further [50]. Likewise, Yang et al. [51] reported that agylcone contents in fermented soybean did not increase upon inoculation with B. subtilis. These contrasting results suggest that changes in isoflavone concentrations and profiles in fermented soybean differ due to thermal processing, temperature, fermentation period, and microorganisms [52].

Fermentation represents a technological alternative to improve cereals functional and nutritional properties [53]. In the current study, the macro and micro nutrients were significantly enhanced in soybean fermented with B. amyloliquefaciens RWL-1 (Table 3). The enhanced minerals contents in fermented soybean are might be due to the bacterial involvement and bacterial interaction with metabolites breakdown $[13,54]$. The similar results of increased nutritional value by degrading and decreasing anti-nutritional and improving the bioavailability of health beneficial minerals in soybean upon fermentation is reported [13]. However, the total mineral contents in soybean fermented with conventional B. subtilis were $13,816 \pm 23 \mathrm{mg} / \mathrm{kg}$ while the total mineral contents in fermented soybean was significantly improved and revealed $16,363.42 \pm 17 \mathrm{mg} / \mathrm{kg}$ with $32.71 \%$ increase.

\section{Materials and Methods}

\subsection{Chemicals}

All chemicals, reagents, solvents, and standards used in the experiments were obtained from Sigma Chemical Co. (St. Louis, MO, USA). Doubled distilled deionized water was used in all experiments. All chemicals were of analytical grade.

\subsection{Microorganism and Soybean Material}

Seed-borne endophytic B. amyloliquefaciens RWL-1 used in current experiment was previously isolated from rice seeds and its sequence is submitted to NCBI (Bethesda, MD, USA) under the accession number KR677384 and reported for antifungal potential and various secondary metabolites production [17-20]. In the current experiment B. amyloliquefaciens RWL-1 was grown in LB medium (Luria-Bertani) at $28^{\circ} \mathrm{C}$.

Soybean cultivar (Aga 3) was selected based on the results of our previously reported work [12] and was obtained from the genetic resource center, Kyungpook National University, Daegu, South Korea.

\subsection{Preparation of Fermented Soybeans}

Preparation of fermented soybeans (FS) was carried out by the method of Ali et al. [13] with some modifications. Soybeans were sorted, washed, and soaked in distilled water for $12 \mathrm{~h}$ at room temperature. After draining, soybeans were heated for $15 \mathrm{~min}$ at $121^{\circ} \mathrm{C}$. The steamed soybeans 
were left to stand for $2 \mathrm{~h}$ at $40 \pm 1{ }^{\circ} \mathrm{C}$ to cool down. Then cooked soybeans were inoculated with $1 \%, 3 \%$, and 5\% (v/w) B. amyloliquefaciens RWL-1 and fermented in an incubator for $60 \mathrm{~h}$ at $40 \pm 2{ }^{\circ} \mathrm{C}$. This experiment was repeated three times.

\subsection{Preparation of Sample Extraction}

Extractions were carried out by the method of Ali et al. $[12,13]$ with some modifications. Briefly, $10 \mathrm{~g}$ of each ground freeze-dried sample was shaken in $50 \mathrm{~mL}$ of $80 \%$ methanol at $37^{\circ} \mathrm{C}$ for $24 \mathrm{~h}$. The incubated extract centrifuged at $3000 \mathrm{rpm}$ for $20 \mathrm{~min}$. The supernatant was then filtered through a 0.45- $\mu \mathrm{m}$ Millipore PVDF filter (Schleicher and Schuell, GmbH, Dassel, Germany). The filtrate was used for assays of polyphenolic compounds and antioxidant activities.

\subsection{Determination of Total Phenolic Contents}

The Folin-Ciocalteu method was used to determine the amount of total phenolic contents according to the method described by Ali et al. [12] Fifty microliters of methanolic extract was added to $1 \mathrm{~mL}$ aqueous solution of $2 \%$ sodium carbonate $\left(\mathrm{Na}_{2} \mathrm{Co}_{3}\right)$ and was left for $3 \mathrm{~min}$. The mixture was mixed with $50 \mu \mathrm{L}$ of $1 \mathrm{~N}$ Folin-Ciocalteu reagent and incubated in the dark for $30 \mathrm{~min}$ at room temperature. The absorbance of the reaction mixture was read at $750 \mathrm{~nm}$ using a Multiskan GO Microplate Spectrophotometer (Thermal Fischer Scientific, Vantaa, Finland). The standard calibration curve was plotted using gallic acid. The total phenolic contents were expressed as milligram gallic acid equivalent per gram of dried sample (mg GAE/g).

\subsection{DPPH Radical Scavenging Activity}

The DPPH radical-scavenging effect of non-fermented and fermented soybean was measured as described by Bilal et al. [55] with some modifications. Briefly, freshly prepared DPPH solution in methanol was used for the experiment. A mixture of equal volumes of methanol extracted samples and freshly prepared $0.1 \%$ DPPH solution was left in dark for $30 \mathrm{~min}$ at ambient temperature. After the incubation period, the absorbance was measured at $517 \mathrm{~nm}$. The inhibitory percentage of DPPH was calculated according to the following equation:

Scavenging effect $(\%)=1$ (absorbance of sample/absorbance of control) $\times 100$

\subsection{ABTS Radical-Scavenging Activity}

The antioxidant activity of the fermented and non-fermented soybean was measured by the ABTS radical cation decolorization assay involving preformed ABTS radical cations [55]. ABTS was dissolved in $0.01 \mathrm{M}$ sodium phosphate buffer to a $7 \mathrm{mM}$ concentration. The ABTS was produced by reacting ABTS stock solution with $2.45 \mathrm{mM}$ potassium persulfate (final concentration) and allowing the mixture to stand in the dark at room temperature for 12 to $16 \mathrm{~h}$ before use. The stock solutions of the soybean extracts in methanol were diluted so that a $2 \mu \mathrm{L}$ aliquot of each dilution was used in the assay. After the addition of $200 \mu \mathrm{L}$ of the diluted ABTS solution to the antioxidant compounds or Trolox standards in methanol, samples were taken at $37^{\circ} \mathrm{C}$ exactly $7 \mathrm{~min}$ after initial mixing. The absorbance of the resulting solution was measured at $734 \mathrm{~nm}$.

\subsection{Free Amino Acid Analysis}

The free amino acid composition of freeze-dried samples was determined according to our previous study [18]. Briefly, the amino acid composition in all treatments was determined with a Hitachi Amino Acid Analyzer (L-8900, Hitachi, Tokyo, Japan) after hydrolysis of $100 \mathrm{mg}$ protein with $6 \mathrm{M} \mathrm{HCl}$ at $110^{\circ} \mathrm{C}$ for $24 \mathrm{~h}$. An amino acid standard mixture solution for automatic amino acid analysis (Type $\mathrm{H}$, Wako Pure Chemical Industries Ltd., Osaka, Japan) was used for the quantification of endogenous amino acid content. All of the samples were run in triplicate and expressed in $\mathrm{mg} / 0.1 \mathrm{~g}$ dry weight. 


\subsection{Determination of Isoflavones}

Isoflavone determination was carried out according to the protocol described by Ali et al. [12] Briefly, $1 \mathrm{~g}$ of grinded sample was defatted and extracted with $5 \mathrm{~mL}$ Hexane and extraction buffer ( $5 \mathrm{~mL}$ acetonitrile, $4.5 \mathrm{~mL}$ water, and $0.5 \mathrm{~mL}$ of the internal standard THB $(0.5 \mathrm{mg} / \mathrm{mL})$, respectively. The extracted samples were centrifuged at $10,000 \times g$ to collect the supernatant. The obtained supernatant was concentrated by evaporation, filtered and injected to HPLC equipped with a Symmetry C18 column (Water, Milford, MA, USA). The UV detector was stabilized with a mobile phase (A: Acetonitrile, B: HPLC water ( $1 \%$ acetic acid), A: 5\% (1 min), 5\% $\rightarrow 35 \%$ (50 min), 35\% $\rightarrow 5 \%$ (5 min), 5\% (15 min) at a flow rate of $1.0 \mathrm{~mL} / \mathrm{min})$. The effluent was detected at $254 \mathrm{~nm}$. The isoflavones were identified by their retention times of standard and were calculated by comparing their peak areas with those of standards.

\subsection{Assessment of Minerals}

Mineral content was determined following the method of Ali et al. [13] with some modifications. Sample powder $(0.5 \mathrm{~g})$ and $\mathrm{HNO}_{3}(15.0 \mathrm{~mL})$ were mixed into a cup. The mixture was diluted with an equal volume of distilled water. Mineral concentrations were determined using an inductively coupled plasma atomic emission spectrometer (ICP AES: Varian Vista, Varian Australia, Victoria, Australia).

\subsection{Statistical Analysis}

The data collected from the triplicate experiments were pooled together and expressed as mean \pm SD. The collected data from the different treatments have been equally compared and subjected to Duncan's multiple range tests (DMRT) using SAS (Version 9.3, SAS Institute Inc., Cary, NC, USA) to reveal statistical difference among treatments. Moreover, GraphPad Prism (Version 6.0, San Diego, CA, USA) was used for graphical presentations.

\section{Conclusions}

Fermentation is considered an alternative to improve the nutritional properties of functional food. The current study showed the potential of B. amyloliquefaciens RWL-1 at $1 \%$ concentration in nutrient enrichment, enhanced antioxidants properties, amino acids enhancement and improvement of isoflavones contents in fermented soybean. These properties provide attractive possibilities for further utilization of this strain in order to improve the health promoting benefits of functional food. Moreover, further studies are needed for the characterization of specific genes and bioactive compounds responsible for these beneficial properties.

Author Contributions: R.S. presented the idea and design the experiment, S.B. and R.S. carried out the experiment, A.S. and R.S. wrote the manuscript. I.-J.L. supervised the experiments and provided the funding. All authors have read and agreed to the published version of the manuscript.

Funding: This research was supported by Basic Science Research Program through the National Research Foundation of Korea (NRF) funded by the Ministry of Education (2017R1D1A1B04035601).

Conflicts of Interest: The authors declare no conflict of interest.

\section{References}

1. Wang, W.; Bringe, N.A.; Berhow, M.A.; De Mejia, E.G. B-conglycinins among sources of bioactives in hydrolysates of different soybean varieties that inhibit leukemia cells in vitro. J. Agric. Food Chem. 2008, 56, 4012-4020. [CrossRef]

2. Li-Jun, Y.; Li-Te, L.; Zai-Gui, L.; Tatsumi, E.; Saito, M. Changes in isoflavone contents and composition of sufu (fermented tofu) during manufacturing. Food Chem. 2004, 87, 587-592. [CrossRef]

3. Wuttke, W.; Jarry, H.; Seidlová-Wuttke, D. Isoflavones-Safe food additives or dangerous drugs? Ageing Res. Rev. 2007, 6, 150-188. [CrossRef]

4. Fonseca, D.; Ward, W.E. Daidzein together with high calcium preserve bone mass and biomechanical strength at multiple sites in ovariectomized mice. Bone 2004, 35, 489-497. [CrossRef] 
5. Ping, S.P.; Shih, S.C.; Rong, C.T.; King, W.Q. Effect of isoflavone aglycone content and antioxidation activity in natto by various cultures of Bacillus subtilis during the fermentation period. J. Nutri. Food Sci. 2012, 2. [CrossRef]

6. Rai, M.; Agarkar, G. Plant-fungal interactions: What triggers the fungi to switch among lifestyles? Crit. Rev. Microbiol. 2014, 1-11. [CrossRef]

7. Egounlety, M.; Aworh, O.C. Effect of soaking, dehulling, cooking and fermentation with Rhizopus oligosporus on the oligosaccharides, trypsin inhibitor, phytic acid and tannins of soybean (Glycine max Merr.), cowpea (Vigna unguiculata L. Walp) and groundbean (Macrotyloma geocarpa Harms). J. Food Eng. 2003, 56, $249-254$.

8. Ushakova, N.A.; Brodskii, E.S.; Kozlova, A.A.; Nifatov, A.V. Anaerobic solid-phase fermentation of plant substrates by Bacillus subtilis. Appl. Biochem. Microbiol. 2009, 45, 61-67. [CrossRef]

9. Papadaki, A.; Kopsahelis, N.; Mallouchos, A.; Mandala, I.; Koutinas, A.A. Bioprocess development for the production of novel oleogels from soybean and microbial oils. Food Res. Int. 2019, 126, 108684. [CrossRef]

10. Papadaki, A.; Kopsahelis, N.; Freire, D.M.; Mandala, I.; Koutinas, A.A. Olive Oil Oleogel Formulation Using Wax Esters Derived from Soybean Fatty Acid Distillate. Biomolecules 2020, 10, 106. [CrossRef]

11. Jang, W.J.; Lee, J.M.; Hasan, M.T.; Lee, B.J.; Lim, S.G.; Kong, I.S. Effects of probiotic supplementation of a plant-based protein diet on intestinal microbial diversity, digestive enzyme activity, intestinal structure, and immunity in olive flounder (Paralichthys olivaceus). Fish Shellfish Immunol. 2019, 92, 719-727. [CrossRef]

12. Ali, M.; Kim, I.-D.; Bilal, S.; Shahzad, R.; Saeed, M.; Adhikari, B.; Nabi, R.; Kyo, J.; Shin, D.H. Effects of Bacterial Fermentation on the Biochemical Constituents and Antioxidant Potential of Fermented and Unfermented Soybeans Using Probiotic Bacillus subtilis (KCTC 13241). Molecules 2017, 22, 2200. [CrossRef]

13. Ali, M.W.; Shahzad, R.; Bilal, S.; Adhikari, B.; Kim, I.D.; Lee, J.D.; Lee, I.J.; Kim, B.O.; Shin, D.H. Comparison of antioxidants potential, metabolites, and nutritional profiles of Korean fermented soybean (Cheonggukjang) with Bacillus subtilis KCTC 13241. J. Food Sci. Technol. 2018, 55, 2871-2880. [CrossRef]

14. Messina, M.J.; Persky, V.; Setchell, K.D.R.; Barnes, S. Soy intake and cancer risk: A review of the in vitro and in vivo data. Nutr. Cancer 1994, 21, 113-131. [CrossRef]

15. Izumi, T.; Piskula, M.K.; Osawa, S.; Obata, A.; Tobe, K.; Saito, M.; Kataoka, S.; Kubota, Y.; Kikuchi, M. Human nutrition and metabolism soy isoflavone aglycones are absorbed faster and in higher amounts than their glucosides in humans. J. Nutr. 2000, 130, 1695-1699. [CrossRef]

16. Lee, M.K.; Kim, J.K.; Lee, S.Y. Effects of fermentation on SDS-PAGE patterns, total peptide, isoflavone contents and antioxidant activity of freeze-thawed tofu fermented with Bacillus subtilis. Food Chem. 2018, 249, 60-65. [CrossRef]

17. Shahzad, R.; Waqas, M.; Khan, A.L.; Asaf, S.; Khan, M.A.; Kang, S.M.; Yun, B.W.; Lee, I.J. Seed-borne endophytic Bacillus amyloliquefaciens RWL-1 produces gibberellins and regulates endogenous phytohormones of Oryza sativa. Plant Physiol. Biochem. 2016, 106, 236-243. [CrossRef]

18. Shahzad, R.; Khan, A.L.; Bilal, S.; Asaf, S.; Lee, I.J. Plant growth-promoting endophytic bacteria versus pathogenic infections: An example of Bacillus amyloliquefaciens RWL-1 and Fusarium oxysporum f. sp. lycopersici in tomato. Peerj 2017, 5, e3107. [CrossRef]

19. Shahzad, R.; Khan, A.L.; Bilal, S.; Waqas, M.; Kang, S.M.; Lee, I.J. Inoculation of abscisic acid-producing endophytic bacteria enhances salinity stress tolerance in Oryza sativa. Environ. Exp. Bot. 2017, 136, 68-77. [CrossRef]

20. Shahzad, R.; Latif, K.A.; Ali, L.; Bilal, S.; Imran, M.; Choi, K.S.; Al-Harrasi, A.; Lee, I.J. Characterization of new bioactive enzyme inhibitors from endophytic Bacillus amyloliquefaciens RWL-1. Molecules 2018, 23, 114. [CrossRef]

21. Lorenzo, J.M.; Munekata, P.E.; Gomez, B.; Barba, F.J.; Mora, L.; Perez-Santaescolastica, C.; Toldra, F. Bioactive peptides as natural antioxidants in food products-A review. Trends Food Sci. Technol. 2018, 79, 136-147. [CrossRef]

22. Conlon, M.; Bird, A. The impact of diet and lifestyle on gut microbiota and human health. Nutrients 2015, 7, 17-44. [CrossRef]

23. Hong, H.A.; Le, H.D.; Cutting, S.M. The use of bacterial spore formers as probiotics. FEMS Microbiol. Rev. 2005, 29, 813-835. [CrossRef]

24. Rizzo, G.; Baroni, L. Soy, soy foods and their role in vegetarian diets. Nutrients 2018, 10, 43. [CrossRef]

25. Johnson, L.A.; White, P.J.; Galloway, R. Soybeans: Chemistry, Production, Processing, and Utilization; Elsevier: Amsterdam, The Netherlands, 2015. 
26. Tungmunnithum, D.; Thongboonyou, A.; Pholboon, A.; Yangsabai, A. Flavonoids and other phenolic compounds from medicinal plants for pharmaceutical and medical aspects: An overview. Medicines 2018, 5, 93. [CrossRef]

27. Hu, Y.; Ge, C.; Yuan, W.; Zhu, R.; Zhang, W.; Du, L.; Xue, J. Characterization of fermented black soybean natto inoculated with Bacillus natto during fermentation. J. Sci Food Agric. 2010, 90, 1194-1202. [CrossRef]

28. Dajanta, K.; Apichartsrangkoon, A.; Chukeatirote, E. Antioxidant properties and total phenolics of Thua Nao (a Thai fermented soybean) as affected by Bacillus fermentation. J. Microb. Biochem. Technol. 2011, 3, 056-059. [CrossRef]

29. Sanjukta, S.; Rai, A.K.; Muhammed, A.; Jeyaram, K.; Talukdar, N.C. Enhancement of antioxidant properties of two soybean varieties of Sikkim Himalayan region by proteolytic Bacillus subtilis fermentation. J. Funct. Foods 2015, 14, 650-658. [CrossRef]

30. Ozgen, M.; Reese, R.N.; Tulio, A.Z.; Scheerens, J.C.; Miller, A.R. Modified 2, 2-azino-bis-3-ethylbenzothiazoline6-sulfonic acid (ABTS) method to measure antioxidant capacity of selected small fruits and comparison to ferric reducing antioxidant power (FRAP) and 2, 2'-diphenyl-1-picrylhydrazyl (DPPH) methods. J. Agric. Food Chem. 2006, 54, 1151-1157. [CrossRef]

31. Sowndhararajan, K.; Kang, S.C. Evaluation of in vitro free radical scavenging potential of Streptomyces sp. AM-S1 culture filtrate. Saudi J. Biol. Sci. 2013, 20, 227-233. [CrossRef]

32. Cho, K.M.; Lee, J.H.; Yun, H.D.; Ahn, B.Y.; Kim, H.; Seo, W.T. Changes of phytochemical constituents (isoflavones, flavanols, and phenolic acids) during cheonggukjang soybeans fermentation using potential probiotics Bacillus subtilis CS90. J. Food Compos. Anal. 2011, 24, 402-410. [CrossRef]

33. Shon, M.Y.; Lee, J.; Choi, J.H.; Choi, S.Y.; Nam, S.H.; Seo, K.I.; Lee, S.W.; Sung, N.J.; Park, S.K. Antioxidant and free radical scavenging activity of methanol extract of chungkukjang. J. Food Compos. Anal. 2007, 20, 113-118. [CrossRef]

34. Shin, E.C.; Lee, J.H.; Hwang, C.E.; Lee, B.W.; Kim, H.T.; Ko, J.M.; Baek, I.Y.; Shin, J.H.; Nam, S.H.; Seo, W.T.; et al. Enhancement of total phenolic and isoflavone-aglycone contents and antioxidant activities during Cheonggukjang fermentation of brown soybeans by the potential probiotic Bacillus subtilis CSY191. Food Sci. Biotechnol. 2014, 23, 531-538. [CrossRef]

35. Hwang, C.E.; Seo, W.T.; Cho, K.M. Enhanced antioxidant effect of black soybean by Cheonggukjang with potential probiotic Bacillus subtilis CSY191. Korean J. Microbiol. 2013, 49, 391-397. [CrossRef]

36. Akhavan, M.; Jahangiri, S.; Shafaghat, A. Studies on the antioxidant and antimicrobial activity and flavonoid derivatives from the fruit of Trigonosciadium brachytaenium (Boiss.) Alava. Ind. Crop. Prod. 2015, 63, 114-118. [CrossRef]

37. Chen, X.M.; Tait, A.R.; Kitts, D.D. Flavonoid composition of orange peel and its association with antioxidant and anti-inflammatory activities. Food Chem. 2017, 218, 15-21. [CrossRef]

38. Damodaran, S.; Parkin, K.L. Amino acids, peptides, and proteins. In Fennema's Food Chemistry 4; CRC Press: Boca Raton, FL, USA, 2017; pp. 235-356.

39. Sarkar, P.K.; Jones, L.J.; Craven, G.S.; Somerset, S.M.; Palmer, C. Amino acid profiles of kinema, a soybean-fermented food. Food Chem. 1997, 59, 69-75. [CrossRef]

40. Dajanta, K.; Apichartsrangkoon, A.; Chukeatirote, E.; Frazier, R.A. Free-amino acid profiles of thua nao, a Thai fermented soybean. Food Chem. 2011, 125, 342-347. [CrossRef]

41. Lee, M.Y.; Park, S.Y.; Jung, K.O.; Park, K.Y.; Kim, S.D. Quality and functional characteristics of chungkukjang prepared with various Bacillus sp. isolated from traditional chungkukjang. J. Food Sci. 2005, 70, M191-M196. [CrossRef]

42. Shahzad, R.; Khan, A.L.; Waqas, M.; Ullah, I.; Bilal, S.; Kim, Y.H.; Asaf, S.; Kang, S.M.; Lee, I.J. Metabolic and proteomic alteration in phytohormone-producing endophytic Bacillus amyloliquefaciens RWL-1 during methanol utilization. Metabolomics 2019, 15, 16. [CrossRef]

43. Li, P.; Yin, Y.L.; Li, D.; Kim, S.W.; Wu, G. Amino acids and immune function. Br. J. Nutr. 2007, 98, $237-252$. [CrossRef]

44. Hu, C.; Wong, W.T.; Wu, R.; Lai, W.F. Biochemistry and use of soybean isoflavones in functional food development. Crit. Rev. Food Sci. Nutr. 2019, 59, 1-15. [CrossRef]

45. Chun, J.; Kim, J.S.; Kim, J.H. Enrichment of isoflavone aglycones in soymilk by fermentation with single and mixed cultures of Streptococcus infantarius 12 and Weissella sp. 4. Food Chem. 2008, 109, 278-284. [CrossRef] 
46. Shon, M.Y.; Seo, K.I.; Lee, S.W.; Choi, S.H.; Sung, N.J. Biological activities of chungkugjang prepared with black bean and changes in phytoestrogen content during fermentation. Korean J. Food Sci. Technol. 2000, 32, 936-941.

47. Barbosa, A.C.; Lajolo, F.M.; Genovese, M.I. Influence of temperature, $\mathrm{pH}$ and ionic strength on the production of isoflavone-rich soy protein isolates. Food Chem. 2006, 98, 757-766. [CrossRef]

48. Lee, D.H.; Kim, M.J.; Ahn, J.; Lee, S.H.; Lee, H.; Kim, J.H.; Park, S.H.; Jang, Y.J.; Ha, T.Y.; Jung, C.H. Nutrikinetics of isoflavone metabolites after fermented soybean product (cheonggukjang) ingestion in ovariectomized mice. Mol. Nutr. Food Res. 2017, 61, 1700322. [CrossRef]

49. Nakajima, N.; Nozaki, N.; Ishihara, K.; Ishikawa, A.; Tsuji, H. Analysis of isoflavone content in tempeh, a fermented soybean, and preparation of a new isoflavone-enriched tempeh. J. Biosci. Bioeng. 2005, 100, 685-687. [CrossRef]

50. Choi, U.K.; Kim, M.H.; Lee, N.H.; Jeong, Y.S.; Kwon, O.J.; Kim, Y.C.; Hwang, Y.H. The characteristics of cheonggukjang, a fermented soybean product, by the degree of germination of raw soybeans. Food Sci. Biotechnol. 2007, 16, 734-739.

51. Yang, S.O.; Chang, P.S.; Lee, J.H. Isoflavone distribution and $\beta$-glucosidase activity in cheonggukjang, a traditional Korean whole soybean-fermented food. Food Sci. Biotechnol. 2006, 15, 96-101.

52. Cho, K.M.; Hong, S.Y.; Math, R.K.; Lee, J.H.; Kambiranda, D.M.; Kim, J.M.; Islam, S.M.; Yun, M.G.; Cho, J.J.; Lim, W.J.; et al. Biotransformation of phenolics (isoflavones, flavanols and phenolic acids) during the fermentation of cheonggukjang by Bacillus pumilus HY1. Food Chem. 2009, 114, 413-419. [CrossRef]

53. Achi, O.K.; Asamudo, N.U. Cereal-based fermented foods of Africa as functional foods. In Bioactive Molecules in Food; Springer Nature: Cham, Switzerland, 2018; pp. 1-32. [CrossRef]

54. Maria, J.K.M.; Enkhtaivan, G.; Lee, J.; Thiruvengadam, M.; Keum, Y.S.; Kim, D.H. Spectroscopic determination of metabolic and mineral changes of soya-chunk mediated by Aspergillus sojae. Food Chem. 2015, 170, 1-9. [CrossRef]

55. Bilal, S.; Khan, A.L.; Waqas, M.; Shahzad, R.; Kim, I.D.; Lee, I.J.; Shin, D.H. Biochemical constituents and in vitro antioxidant and anticholinesterase potential of seeds from native Korean persimmon genotypes. Molecules 2016, 21, 893. [CrossRef]

Sample Availability: Samples of the Bacillus amyloliquefaciens RWL-1 are available from the authors.

(C) 2020 by the authors. Licensee MDPI, Basel, Switzerland. This article is an open access article distributed under the terms and conditions of the Creative Commons Attribution (CC BY) license (http://creativecommons.org/licenses/by/4.0/). 